the joint $(e)$, and thus the tissues are constricted to any requisito degreo in an elliptical manner.

In applying the clamp, the arm $(d)$ is to bo opened by unscrewing the nut $(f)$, and then passed around the pedicle and closed again, and made fast as before, the slide $(c)$, having previously been scrowed back towards the handle.

If the clamp is to be used instead of the ligature, after sufficient compression of the pedicle, the handlo $(a)$ and the wheel $(b)$ are to be removed by unscrewing them, which renders the clamps much lighter and perfectly flat, so that no inconvenience is caused by its resting on the abdomen.

The dotted outlines $(g)$ in the cut show the arm of the clamp opened ready for application and needs no particular explanation.

Besides the purpose for which this clamp was originally designed, it may advantageously be used in the removal of hamorrhoids, portions of the tongue, penis, scrotum, and extraneous growths.

The entire instrument is so light, compact and small that its case may be carried in tho vest-pocket without inconvenience. It is manufactured by G. Tiemann \& Co., 67 Chatham Street, New York.

\section{A CASE OF ULCUS SERPIGINOSUM SYPIILI'TICUN.}

By J. C. MaY, Jn., M.D), Surgeon to the New York l)ispensialy, Department of Vencreal and Skin Dise:ises.

D. C. R. presented himself to me $\Lambda$ ugust 5 th, $187 \mathrm{~L}$, with the following listory :-Nattive of the United States, tinsmith, 31 years of age, married, has two children aged 10 and 6 years. Ilis wife has had one miscarriage between the two children. $R$. contracted two sores upou his penis in November, 1868 . T'hese did not heal until the following March, and during January they caused codema and phymosis. Had a papular eruption upon the body and extremities in May, which disappeared in August. In Junc, 1869, lad two sore spots along side of the arms, which healed in a month upon the application of a caustic. Underwent mercurial treatment for three weeks during the existence of the primary sores. Noticed at that time three kernels in the right groin.

In the winter of 1869-70, he had another eruption upon the body and extremities similar in nature to the previous one. $\Lambda$ t the same time he had some scabs upon his scalp. 'The eruption disappeared carly in the spring of 1870 , when ulcerations began upon tho right shoulder and right forearm. In the fall of the same year, the right shoulder healed, and in February, 1871, the right forearm healed. In March, 1871, ulceration began upon the left forearm, and healed completely by the middle of June, to break out again early in July, producing ulccrations, which are now present. Ulceration of the left shoulder began in March, 1871, accompanied by a discharge more profuse than that of the other ulcers. This shoulder healed and broke out again, and is at present completely healed. R. has not had iritis, nor alopecia, nor rlreunatism, nor sore throat. Hias noticed during tho past year a laud prominence upon the anterior surface of the right tibia, which has never caused pain savo when pressed upon. Had typhoid fever in 1862. Never harl any sores previous to 1868 . Ilas had gonorthoea once.

Present Condition.-The seat of the initial lesion does not sliow any cicatrix or induration. Varicocele of the left side. $\Lambda$ node upon the anterior surfice of the right tibia, sensitive to pressure. Inguinal and brachial glands enlarged and indurated. 'Two cicatricial surfaces upon the posterior aspect of both shoulilers, each having an irregularly circular outline and a diameter of four inches. $\Lambda$ cicatrix upon the right arm and forearm, involving the posterior and external surface of the elbow-joint, and the whole upper half of the external surfice of the forearm. A cicatricial and ulcerating surfice upon, the left arm, involving almost completely the entire surface of the lower third of the arm and upper half of the forearm. The nleers upon this surface are three in number. Wach is in the shape of a perfect crescent. 'The three of similar size. 'The distane between the two horns of each crescent measures two inches. These crecping ulecrs present il healthy, florid, clean appearance, their surfaces very slightly depressed below the surrounding surface, and their discharge is of a thin serous character. Fdge of the convex border not undermined or differing in aspect from the edge of the concave border. 'Two of these ulcers were advancing in cicatricial tissue, the other in normal integument. They cause the patient no pain. 'The cicatrix involving the thoxor surface of the left elbow has contracted somewhat, rendering it jmpossible to completely exteud the forearm upon the arm. 'This causes the patient some inconvenience in his trade. IIe says that the ulcers which produced the cicatrices upon the shoulders and right arm 
were similar in shape and appearance to those now present upon the right arm. He does not cxpress any anxicty about the latter, as he is sure they will heal, but wishes to get some medicine to purify his blood and prevent their return. IIis general licalth is very good.

Ordered the following treatment:

P Ilydrarg. chlor. cor. gr. ij. Potass. iodidi. Aquas

3 iv.

M. One teaspoonful in a wineglass of water, after eacli meal.

13 Ungt. hydrarg. ox, rub.

Ungt. simplicis, partes aquales.

M. et ft. ungt. 'To be applied to the ulcers.

August 20th.-The ulcers have nearly cicatrized, and the patient is apprehensive that they have been healed too rapidly.

1)r. Jimanuel Koln, in an exhaustive treatise upon ulcus serpiginosum, published in a recent number of the Archiv fiir Dermatologie und Syphitis, describes an ulcer serpiginous in character, but differing in every other respect from that descrilsed in the above case, and he concludes that serpiginous ulcers, as described by him, are of a non-syplititic origin. The ulcers in the case I have related, from their shape and mode of progress, are clearly entitled to the epithet serpiginous, and from the his$t_{\text {ory }}$ of the case and the results of treatment, are of undoubted syphilitic origin, leading to but one conclusion, that two serpiginous ulecrs may be met with. 'The one, so well and minutely described by Dr. Kohn, nonsyphilitic, obstinatc, and intractable in its character; the other dno to syphilis, and readily amenable to anti-syphilitic remedies. -The American Journal of Syphilography and Dermatology.

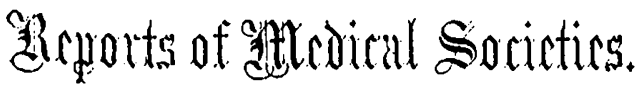

TIIE JOSTON SOCIETX OF MEIICAL SCIENCES. J. ORNE GRELN, M.D., SlECRETARY.

OCr. 3d, 1871.-Whe Society met at the house of Dr. White. Dr. Wausworth in the cliail.

Dr. White read a paper on the protection acquired by the human skin (and other tissues) agrainst the action of certain animal poisons after repeated inoculation, claiming that the frequent inoculation of some poisons gave a gradual immunity from any poisonous effects. IIe instanced the ef- fects of mosquito bites, which he thought were more severe in clildren than in adults, much more severe in foreigners who had recently arived in this comtry than in natives, and in support of this spoke of a whole family, recently arrived from England, which he had just seen, upon the members of which the bites of mosquitoes had produced a violent eruption of the skin resembling pemphigus. Ile thought that the immunity derived from frequent inoculations was analogous to that from vaccine matter against variola.

In reply to questions, 1)r. White said that he considered it as established that poisonous suakes were not killed by their own poisons; insects, however, he said, did not enjoy this immunity, as wasps and bees were known to kill each other by their poison.

J)r. Amory said, in support of Dr. Whito's theory, that in regions where black flies abound, persons after a few years are not atlected by the poison. 'This immunity is not obtained in one season, but only after a prolonged residence; such persons are bitten as at first, but escape all the disagreeable eflects from which a non-resident suffers.

Dr. Wigglesworth asked how it was, then, that in persons affected for many years with lice we sec no cessation in the toxical action of the bites upon the skin; as is shown by the non-cessation from scratching and the progressive severity of the affection, so that in old cases we see a marked increase in the deposition of pigment in the skin.

1)r. White thought that the sulpjective symptoms were different after a time from those felt at first; that the lice coase to irritate and aro not felt; the increased pigment he thought was due to the blood drawn to the skin by the increased number of bites.

3)r. Fitz thought that the continuous eczema kept up the seritching.

1)r. Nichols considered it a fact that children sufler most from mosquito-bites, and ho had known such bites $t$ ) be mistaken by the family for chickempox and even smallpox.

1)r. 1)wight showed a specimen which he said was rare in this countly; it was the complete osseous auditory apjaratus of the common fimner [ 13alonopteral musculus] and was the property of the Boston Society of Natural 1listory. It consisted of the ossicula, the tympanum and labyrinth, the two latter opened so as to show their interiors, and had been prepared by him recently. He said :- 